\title{
Aula Touch Game: Digital Tablets and Their Incidence in the Development of Citizen Competences of Middle Education Students in the District of Barranquilla-Colombia
}

\author{
Paola Patricia Ariza Colpas ${ }^{1(\otimes)}$, Belina Annery Herrera Tapias ${ }^{1}$, \\ Andres Gabriel Sanchez Comas ${ }^{1}$, Marlon Alberto Piñeres Melo ${ }^{2}$, \\ and Judith Martinez Royert ${ }^{3}$ \\ 1 Universidad de la Costa, CUC, Barranquilla, Colombia \\ \{pariza1, bherrera, asanchez\} @cuc.edu.co \\ ${ }^{2}$ Universidad del Norte, Barranquilla, Colombia \\ pineresmauninorte. edu.co \\ ${ }^{3}$ Universidad Simon Bolivar, Barranquilla, Colombia \\ Judith.martinez@unisimonbolivar.edu.co
}

\begin{abstract}
Citizen competences are considered as a fundamental aspect in the social development of man with his environment, which allows him to carry out actions that are articulated with the different guidelines established by law, which leads the citizen to live in a coherent and peaceful way in a nation that tends for freedom of thought framed in a democratic society. That is why it is considered of high importance that in educational establishments there are spaces that tend for training in peaceful coexistence framed in the law of the educated. This article resulted from the research project: "Social Appropriation of citizen and mathematical competences making use of MIDTablets", in which the mediation of Information and Communication Technologies is proposed to support the training of citizens with competences citizens who ensure adequate behavior in society. This project was developed in 31 educational institutions in the district of Barranquilla-Colombia, with support from resources of both the Ministry of Information Technology and Communications (MinTic), and the Secretariat of District Education of Barranquilla, in compliance with national goals, departmental and district regarding the quality of education of the national population
\end{abstract}

Keywords: Digital tablets · Citizen competences - Social appropriation · Middle education $\cdot$ Learning software

\section{Introduction}

Postmodernity and globalization have brought with it the application of technological tools that have the property of making available to people an accumulation of information that facilitates the construction and transfer of knowledge [1]. The inclusion of these technologies in the teaching and learning processes allows education to reach more and 
more remote places [2]. The use of different technological and communication tools that have proliferated in recent years through the internet and the increasing incorporation of different resources and tools other than the computer, such as mobile devices: Tablets, Ipad, Cellular, Smartphone, among other devices, they make possible their incorporation into education and have given a new dimension to learning. In fact, this has to do with the desire of the human being to stay educated and updated throughout his life not only through face-to-face training scenarios but also through virtual media training scenarios, which allows them to access information and knowledge from anywhere and at any time with basic technical conditions of access [3, 4].

The National government is aware of the need to improve the quality of education at all levels, which is evidenced in the Sector Plan (2016-2019) of the Ministry of National Education, which highlights that the quality of education is related to multiple factors: the teaching and learning methodologies, the training of its educators, the evaluation systems implemented, the way in which the levels of training are articulated, the institutional capacity and infrastructure and the conceptual and legal framework that organizes and supports the educational system, through which it is made explicit that quality education is a right that all citizens must access. Consequently, teacher qualification in the educational incorporation of tablets in the classroom that responds to a pedagogical model, will contribute to improving the educational quality in the district of Barranquilla.

The District of Barranquilla has 152 educational institutions at levels ranging from early childhood to secondary education, institutions that according to studies by the District Mayor in its program "A Safer Barranquilla" has identified problems of violence and conflicts that threaten the human rights of children and adolescents, the fracture of the social fabric, the quality of life in our local environment. Against this background, it has been shown that education is the most important instrument for the recognition and management of conflict through peaceful mechanisms that generate school environments of reconciliation, democracy and peace, so that direct action is necessary that It can generate a social appropriation of mechanisms that contribute to the construction of satisfactory, reciprocal and participatory solutions of school actors who present antagonistic arguments, which in many cases leads to mutual psychological, physical and sexual aggression; and thus reflect a change in the behaviors of communities traditionally do not have developed citizen competencies.

In this project, 31 district educational institutions of strata 1 and 2 of the District of Barranquilla were intervened, in addition to generating conceptual, technological and methodological tools, within the framework of the development of citizen competencies through the conceptualization of friendly and peaceful solutions of the controversies that threaten human rights, for the integration of a network that generates direct actions on the community, in which the academic, research and innovation experience in the environment would be combined, as a form of positive intervention in the face of the social need of the District of Barranquilla and its metropolitan area.

\section{The Conflict Resolution, National Bet for Coexistence}

Conflict resolution is a fundamental aspect in which respect for the needs, tastes, points of view and values of different individuals converge, which is why it is quite probable 
that they can be generated $[5,6]$. There are different stages to be addressed to support conflict resolution, which are focused on mitigating or reducing the consequences that may arise from their appearance [7, 8].

In the Barranquilla district, a phenomenon of conflicts has been identified with reference to school coexistence and human resources in district institutions. Regarding bullying among school students, the World Health Organization (WHO), in data from 35 countries, reports that $15 \%$ of 11 -year-olds and $9 \%$ of 15 -year-olds have been intimidated at some point. According to UNESCO statistics, in works carried out between 2009 and 2018, they show that in Latin America 51\% of the 6th grade students surveyed say they have been the victim of insults, threats, bulling and different situations of conflict. In Colombia, $29 \%$ of fifth-graders and $15 \%$ of ninth-graders have been bullied in the past two months, according to a study of 50,000 students reported by the Colombian Parent-Parent Corporation RedPaPaz. The experts cited agree that bullying or bullying is not a problem of children, isolated, but of society, with a common denominator: violence. Consequently, it is possible to assume the problem from an integrated approach to the understanding and approach for the resolution and prevention of school conflict, identifying the factors that generate conflict and its components, valuing the role of communication as a means of conflict resolution, as well as the importance of the mediation process from a systemic perspective in the educational context, reflecting on the different roles and strategies of intervention in the face of school conflict and proposing institutional strategies and alternatives for the development of conflict intervention plans and school mediation [9, 10].

\section{Mediation of ICT in the Development of Citizen Skills}

Through the strategic alliance with government entities in order to implement a program which through the use of digital content in the middle school classrooms of the city, the learning of the student population and educational quality is strengthened of the public institutions of the city. The digital content was developed according to the requirements of the Barranquilla District Education Secretaries, implemented on smart mobile devices, and deployed with a training process for the teachers and staff of these Educational Institutions, see Fig. 1.

Operationally and technically, digital content is installed directly on smart mobile devices through an internet link, which will be downloaded through exclusive permits granted to educational institutions attached to the program. The download will be made from a repository maintained and supported by the Universidad de la Costa Corporation, which will provide a support service and technical assistance during the year of service. With the renewal of the program, digital content will be automatically updated via the internet after the feedback process and quality improvement of these contents. In the same way, new digital content can be installed either to strengthen new themes or other subjects of educational institutions.

Functionally, digital content allows the registration of each student who uses digital content in educational institutions, in order to monitor the student's learning process, in the context of what is being worked on in digital content, as well as the use and exploitation of the student, see Fig. 2. At the end of the year, reports on the use and exploitation of digital content by the institution will be issued. 


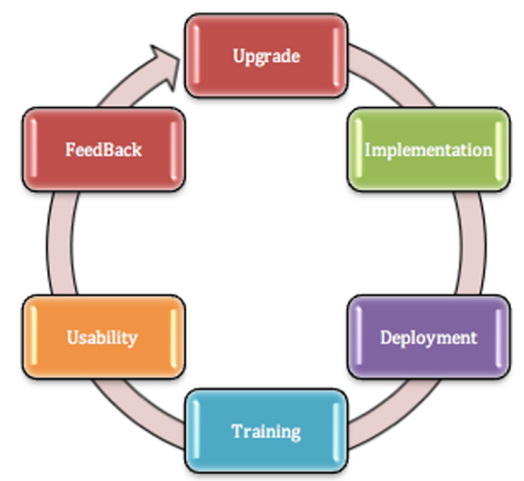

Fig. 1. Application work cycle

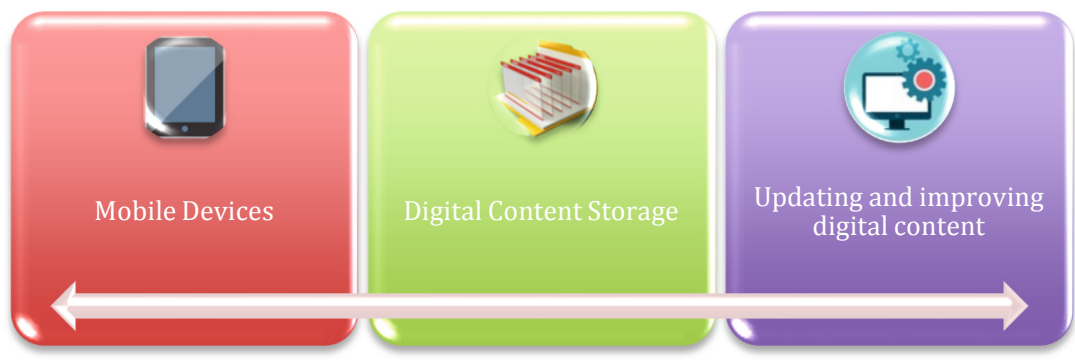

Fig. 2. Components of the solution architecture

\section{Technical Specifications of the Application}

The training strategy was carried out in three ways: use of support applications for the reinforcement and development of learning activities in the areas of mathematics and citizen skills, use of digital content developed by teachers and students in class sessions using the tablets and the use of Digital Content and learning activities developed by the ally that are accessed through a Digital Classroom Touch Classroom. The application has the following characteristics:

- A parameterized Technology Platform was developed that will be hosted in the Cloud (Administrator panel in the Cloud and the client will be developed in the Android Operating System)

- A pilot was carried out with the subjects in the areas of mathematics and Citizen Competencies, emphasizing violence and society, however, the platform will allow Parameterization in such a way that in a future term other subjects in the different areas of knowledge can be referenced that are taught in basic and secondary education.

- An accessed Android client application was installed on the tablets and each of these tablets will have a specific username and password, which will allow the student to access three (3) sessions separated by academic grade (9th, 10th, 11th). Once the user 
enters the platform, the identification code of the mobile device will be linked to the FDI for the purpose of measuring results and statistics.

- A topic was selected: once the grade has been selected, the information regarding the subjects delimited in the previous investigation will be displayed (subject selection, select the Units and then select the specific topic to reinforce).

- Each subject contained content of the respective subject in the formats (Document (PDF), Podcast, MP3, Videos), it will contain a session of examples and evaluation exercises.

- The exercises were developed with 3 degrees of difficulty (basic, medium and advanced), so that the student can advance from one grade to another, they must previously carry out the exercises in the order of the grades, this will allow the motivation of the students as a challenge. that leads to learning. The platform will issue the student a report of their achievements and mistakes made, giving them the opportunity to retake the exercises.

- The exercises were developed taking into account the form of the Saber ICFES tests through questionnaires that will allow students to have a setting of the question and several multiple-choice answers, however the student must carry out the procedure of the exercise prior to selecting the answer. In case the student cannot solve the exercise, the application gives him the opportunity to show how it is solved and gives him the opportunity to do the exercises again. There will be a bank of random questions, this means that the questions are not repeated and that the student may know other options.

- For the administration of the WEB portal, an administrator was assigned to him who, by means of a user and a password, was enabled to create courses, modify, update, upload resources, delete, display and hide and finally enable and disable courses, exercises, topic, among others (upon request of the thematic experts) the following options were included: Creation of courses, units, topics, exercises and questionnaires.

- Taking into account that access is via the Internet, a $2 \mathrm{Mb}$ connection is required, Android operating system.

- All resources (PDF, Videos, PODCAST) can be downloaded by students.

- The client application was created with high usability standards, allowing students greater navigability of the platform, since it will be delimited by specific sessions that will allow them to appropriate the information provided.

- For each student, statistics of student achievement are kept as long as it is arranged with the schools the delivery of the database of the students of 9th, 10th and 11th), this will allow the school to know the academic status of these students. for decision making (Fig. 3).

\section{Methodology for the Development of the Application}

Three phases were carried out for the development of this application, which are detailed below:

- First phase: access to different web pages in order to obtain information on the results of the "Saber 11" tests, the competences that the ICFES evaluates in the areas of mathematics and citizen competences and the guidelines contemplated in the basic 


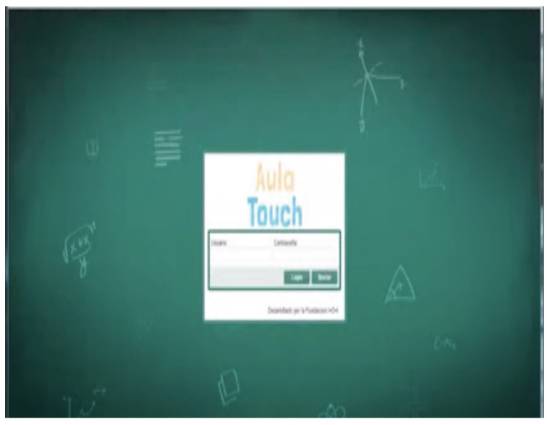

a)

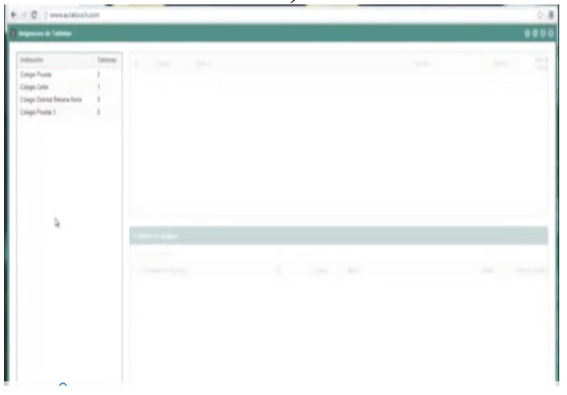

c)

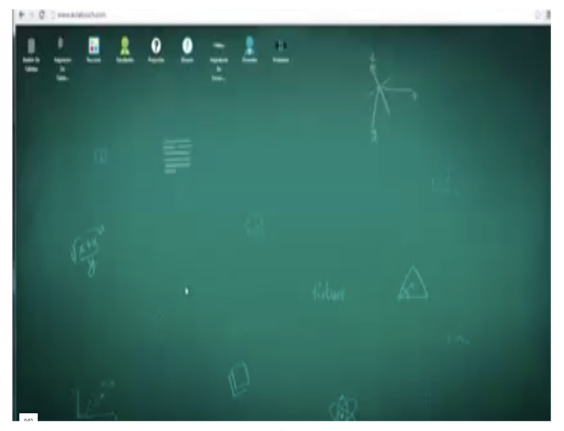

b)

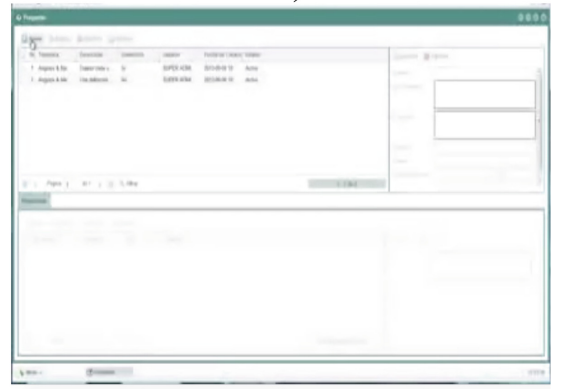

d)

Fig. 3. Aula Touch images: a) Main page of Aulatouch, b) Main menu Aulatouch, c) Adding resources Aulatouch, d) Adding questions AulaTouch

competency standards of the Ministry of National Education where the competences that students must develop in these two areas of knowledge are established.

- Second phase: Review and analysis of the results of the Saber $11^{\circ}$ tests obtained by the 31 Educational Establishments benefiting from the project during 2018, which are shown below in the Fig. 4. In Figs. 4, it is observed that the average obtained in the math tests by the 31 schools was 45.68, of which 16 institutions $(51.61 \%)$ obtained results below this average. Similarly, the national average in the social area, in which the citizen competencies are located, was 43.80, of which 16 (51.61\%) obtained results below the average. These low results demonstrate the need for FDI to reinforce these two areas, for which the strategy of incorporating tablets in the classroom with complementary content constitutes an extremely important opportunity.

- Third phase: Review of the Competences to evaluate in the tests Knowing $11^{\circ}$ in the country: In the Mathematics Area, according to the ICFES, in middle education in the mathematics area, three competences are evaluated: Communication, reasoning and problem solving in the components (variational, geometric-metric and random number). In the area of Citizen Competences: According to ICFES, citizen competences are cognitive, emotional and communicative capacities that, integrated with each other and related to knowledge and attitudes, make it possible for citizens to act actively, in solidarity and democratically in society. 


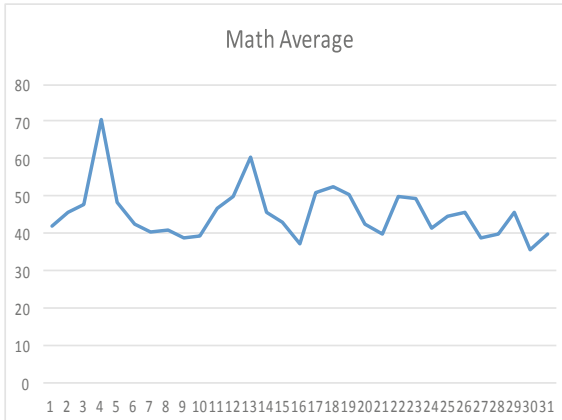

a)

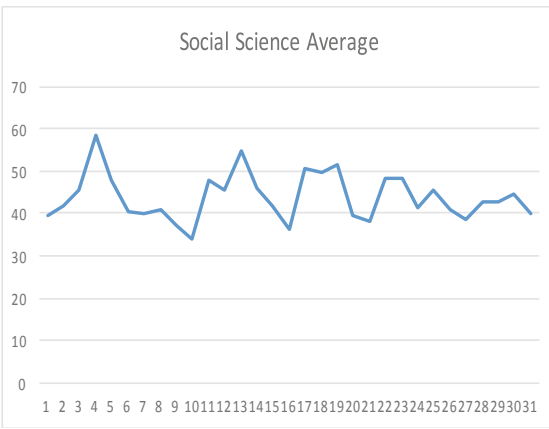

b)

Fig. 4. a) Math Average, b) Social Science Average.

The identification of the problems associated with the areas of Citizen Competences and Mathematics, allowed us to have basic information to select the topics that in these two areas needed to be reinforced in the students. Mathematical problems are learning difficulties that a primary and secondary school student may encounter. It can be for some of the cognitive, physical or mental type, or any social problem in which the students are.

When there is a difficulty in learning mathematics, it is necessary to make a diagnosis, which allows us to know what is really the difficulty that the student presents, or if it refers to a disease, such as dyslexia, dysgraphia, dyspraxia, or other difficulties. It has been determined that in many cases the learning difficulties of the students are associated with many factors, including the methodology used by the teachers, the content, the motivation of the students and the resources made available by the same institution.

In the area of mathematics, it is necessary for students to develop a way of thinking that allows them to mathematically interpret and communicate situations that are presented to them in various sociocultural environments, using appropriate techniques to recognize, pose and solve problems. For the learning of the Citizen Competences, it is necessary that the teachers use innovative pedagogical strategies that allow the students, in addition to acquiring the cognitive competences, to appropriate these concepts and apply it to contextual problems.

\section{Development of the Application Deployment and Launch of the Application}

The students and teachers of the 31 district educational establishments of the project, recognized, developed and approved the citizen competences and after this diagnosis defined strategies that generated significant cultural changes in the students such as: identifying, evaluating and respecting the differences and similarities between the citizens according to the plurality of the Colombian Political Constitution, comply with the minimum standards of coexistence, reject situations of exclusion and discrimination in the classroom, strengthen the recognition and exercise of citizenship, identify mechanisms for citizen participation and express their opinions. 


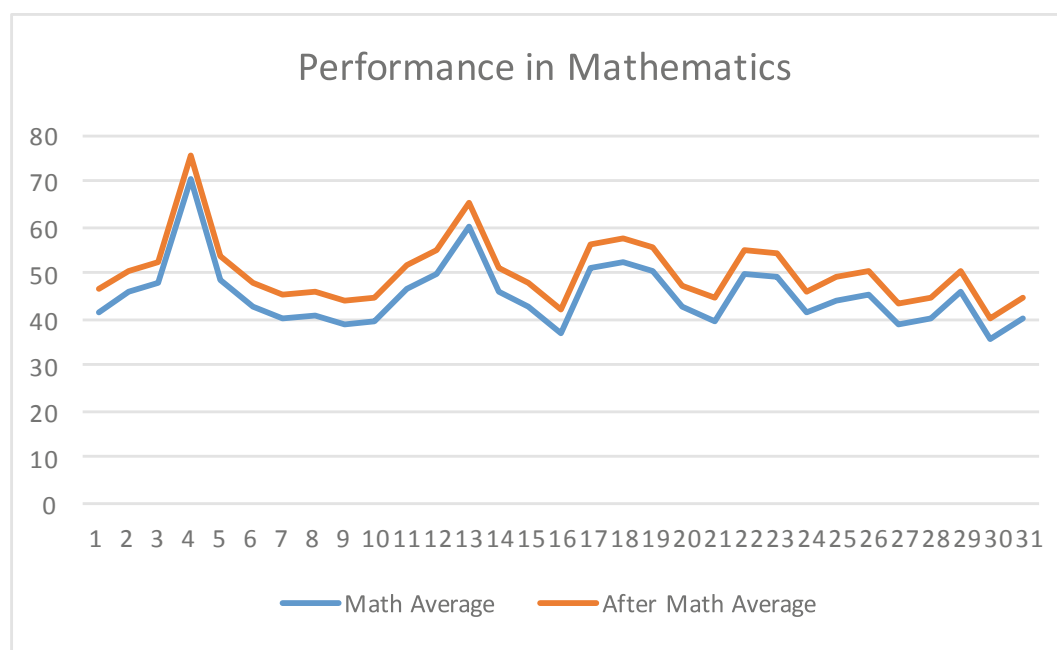

Fig. 5. Comparison of performance in mathematics before and after the use of the tool

Based on the results obtained, a proposal was prepared with the use of Tablets that leads to the development of citizen competencies and the improvement of student results in the Saber $11^{\circ}$ tests. The project is expected to impact the academic community of the Educational Institutions of the Barranquilla district and society in general not only academically but also socially by training committed citizens, respectful of difference and defenders of the common good.

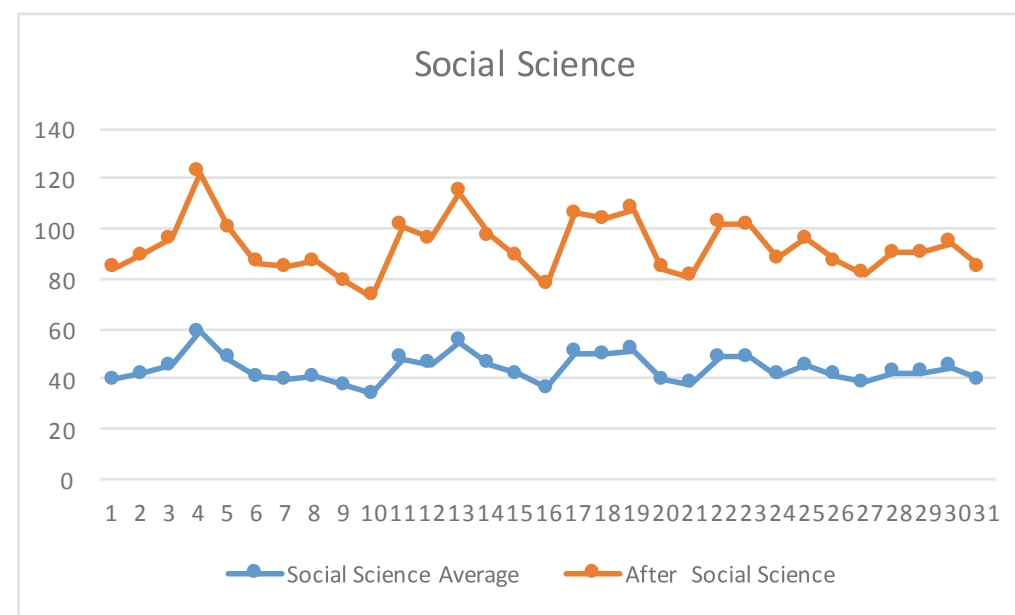

Fig. 6. Comparison of performance in Social Science before and after the use of the tool 
As a result of the implementation of the project, better student performance was achieved in the math and social science tests, as can be seen in the following Figs. 5 and 6.

\section{Conclusions}

- The didactic strategies with the use of tablets incorporated into the educational practice constitutes a significant contribution for the Educational Establishments of the Barranquilla District, since they contribute to the development of the competences of the mathematical students and citizen competences of the students.

- To achieve success in a process of incorporating digital tablets, it is necessary to coherently link technology with pedagogy, since when developing a learning activity with the use of technology, clear pedagogical guidelines must be given and with a pedagogical intention.

- The use of tablets in the classroom during the development of a training process arouses the interest of the students, the debate and the argumentation that allow to improve the way in which the students achieve the learning.

- The use of didactic strategies supported by the use of Tablets, allows a greater interaction between students and teachers during the development of cooperative and collaborative projects.

- With the educational incorporation of ICT in the training processes, it constitutes a fundamental element for the development of collaborative projects aimed at improving the skills of students in the area in which they are used.

\section{References}

1. Zakaria, F., Zukiman, W.W., Shah, A.M.: SAT-482'UR-ine'Town board game: learning AKI the fun way!!! Kidney Int. Rep. 5(3), S201 (2020)

2. Lee, D.: Comparison of reinforcement learning algorithms for a $2 \mathrm{D}$ racing game learning agent. J. Inst. Internet Broadcast. Commun. 20(1), 171-176 (2020)

3. Sopy, H., Hasibuan, S.: Development of game learning media e-learning basketball based on students class X of SMA Negeri 3 Medan. In: 1st Unimed International Conference on Sport Science (UnICoSS 2019), pp. 11-13. Atlantis Press, March 2020

4. Pardede, E.Y.: Development of the snake game model for basic movement skills in SD medan struggle students. In: 1st Unimed International Conference on Sport Science (UnICoSS 2019), pp. 146-147. Atlantis Press, March 2020

5. Nuryasintia, I.: EFEK Moderasi Keaktifan Belajar Siswa Pada Pengaruh Media Monopoly Accounting Game Terhadap Pemahaman Konsep, Doctoral dissertation, Universitas Pendidikan Indonesia (2019)

6. Echeverri-Ocampo, I., Urina-Triana, M., Patricia Ariza, P., Mantilla, M.: El trabajo colaborativo entre ingenieros y personal de la salud para el desarrollo de proyectos en salud digital: una visión al futuro para lograr tener éxito (2018)

7. Morales Ortega, R., Ariza Colpas, P.P., Piñeres-Melo, M., Ayala-Mantilla, C., PeluffoMartínez, G., Mendoza Palechor, F., Diaz Martinez, J.L.: CBT system (Computer Based Training) of the aircraft a-37b, used in the earth course of the combat air command No. 3 (CAMCOM-3) of the Colombian Air Force (FAC) (2020) 
8. Wang, H., Chen, W.W., Sun, C.T.: Play teaches learning?: a pilot study on how gaming experience influences new game learning. In: Interactivity and the Future of the HumanComputer Interface, pp. 147-168. IGI Global (2020)

9. Lubay, L.H., Purnama, A.D.: An effort to improve the playing skill through the application of tool modification in small ball game (a classroom action research). In: 4th International Conference on Sport Science, Health, and Physical Education (ICSSHPE 2019), pp. 403-405. Atlantis Press, February 2020

10. Masyhuri, S.F., Suherman, W.S.: The traditional game learning model for the elementary school student character building. In: 4th International Conference on Sport Science, Health, and Physical Education (ICSSHPE 2019), pp. 9-13. Atlantis Press, February 2020 